\title{
Editorial: Towards Innovation in Next Generation of Wind Turbine Rotor Design
}

\author{
Wei Jun Zhu ${ }^{1 *}$, Wen Zhong Shen ${ }^{1,2}$ and Taeseong Kim ${ }^{2,3}$ \\ ${ }^{1}$ College of Electrical, Energy and Power Engineering, Yangzhou University, Yangzhou, China, ${ }^{2}$ Department of Wind Energy, \\ Technical University of Denmark, Kongens Lyngby, Denmark, ${ }^{3}$ Wolfson School of Mechanical, Electrical and Manufacturing \\ Engineering, Loughborough University, Loughborough, United Kingdom
}

Keywords: wind turbine rotor design, wind turbine aerodynamics, wind turbine aeroelastics, wind turbine aeroacoustics, cost of energy

Editorial on the Research Topic

Towards Innovation in Next Generation of Wind Turbine Rotor Design

\section{INTRODUCTION}

The development of renewable energy is an inevitable response to the dual challenges of the energy crisis and global warming. In many countries, wind energy has become the most cost effective renewable energy relative to other energy sources. In order to reduce the cost of electricity, modern wind turbines are increasing in rotor size and unit power. The big wind turbines currently in the market are reaching $15 \mathrm{MW}$ rated power and will be possibly increased to $20 \mathrm{MW}$ in a few years. In such a scenario, the continued development in wind energy has led to large rotors that are much lighter and cheaper per kilowatt than before. The main innovations include higher tip speed, higher lift and thicker airfoils, resulting in more slender and lighter blades. In the meanwhile, the coupled effects of aeroelastic and aeroacoustic behaviour and modelling have become the key research challenges. Therefore, research in many aspects of wind energy innovation is important, such that the overall objectives of low cost of energy, high system reliability and environmental-friendliness can be achieved. Several rotor design concepts have emerged to satisfy the up-scale trend, but a crucial problem is managing the large inertial loads and aeroelastic response while retaining high aerodynamic efficiency. Further utilizations of wind energy research meet the critical challenge to continuously grow in size and continuously decrease in price per kilowatt.

\section{CURRENT STATUS IN WIND TURBINE ROTOR DESIGN}

This section gives a very brief review of the research history from the current state of art $5 \mathrm{MW}$ machine towards the more challenging design of a $50 \mathrm{MW}$ machine. The $5 \mathrm{MW}$ reference wind turbine has been widely studied from rotor aerodynamic and structure design aspects (Buck and Garvey, 2015; Borouji and Nishino, 2019; Choi et al., 2019). As proposed in (Buck and Garvey, 2015), replacing the blades of a 5 MW wind turbine by a low induction rotor leaded to a reduction in capital cost per unit of annual energy production of over $2 \%$. The same idea of low induction rotor was further employed in the design of a $10 \mathrm{MW}$ wind turbine (Bak et al., 2013). For blade lengths reaching almost $100 \mathrm{~m}$, it was noted that the conventional straight blade and upwind design concept can be further improved (Bortolotti et al., 2019; Sun et al., 2021). It turns out that a downwind non-aligned configuration might be a more interesting alternative (Bortolotti et al., 2019). More solutions for a $10 \mathrm{MW}$ machine are given in (Sun et al., 2021) where different downwind/upwind/ conning/pre-bending rotor configurations were studied in detail as sketched in Figure 1, where wind 


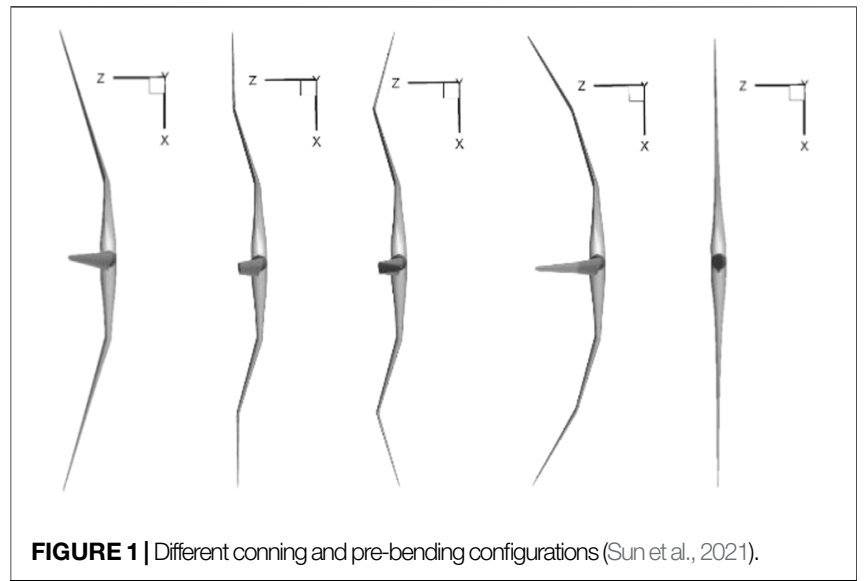

comes from the left hand side. Instead of combining various existing airfoils to build a large blade, the design and optimization process of airfoil shape can be integrated into blade design, which resulted in much higher aerodynamic performance of a $20 \mathrm{MW}$ machine (Zhu et al., 2014). A redesign of a $13.2 \mathrm{MW}$ machine up to $25 \mathrm{MW}$ was achieved with a cone-wise load-alignment arrangement (Qin et al., 2020) which leaded to a useful baseline for further development and assessment of a $50 \mathrm{MW}$ ultra-large machine (Yao et al., 2021), where a baseline $250 \mathrm{~m}$ blade was further optimized with a reduced weight of 25\%. As also stated in (Veers et al., 2019), the science of wind turbine rotor design involves the world largest rotational machines, so the proposed design challenges are tremendous.

\section{FUTURE RESEARCH NEEDS}

Although this Special Issue has now closed, more research more research in advanced wind turbine rotor design technology is

\section{REFERENCES}

Bak, C., Zahle, F., Bitsche, R., Kim, T., Yde, A., Henriksen, L. C., et al. (2013). Description of the DTU 10MW Reference Wind Turbine. Lyngby, Denmark: DTU Wind Energy.

Borouji, E., and Nishino, T. (2019). Fluid Structure Interaction Simulations of the NREL 5MW Wind Turbine-Part I: Aerodynamics and Blockage Effect. J Offshore Mechanics Arctic Engineer-Transactions Asme 141. doi:10.1115/1.4040980

Bortolotti, P., Kapila, A., and Bottasso, C. L. (2019). Comparison between Upwind and Downwind Designs of a $10 \mathrm{MW}$ Wind Turbine Rotor. Wind Energ. Sci. 4, 115-125. doi:10.5194/wes-4-115-2019

Buck, J. A., and Garvey, S. D. (2015). Redefining the Design Objectives of Large Offshore Wind Turbine Rotors. Wind Energy. 18, 58. doi:10.1002/we.1733

Choi, D.-G., Kwak, C.-H., Lee, S.-Y., Bae, J.-S., and Lee, H.-G. (2019). Structural Design and Analyses of a Fabric-Covered Wind Turbine Blade. Adv COMP MAT. 28, 607-623. doi:10.1080/09243046.2019.1626187

Qin, C., Loth, E., Zalkind, D. S., Pao, L. Y., Yao, S., Griffith, D. T., et al. (2020). Downwind Coning Concept Rotor for a 25 MW Offshore Wind Turbine. Renewable Energy 156, 314-327. doi:10.1016/j.renene.2020.04.039

Sun, Z. Y., Zhu, W. J., Shen, W. Z., Tao, Q. H., Cao, J. F., and Li, X. C. (2021). Numerical Simulations of Novel Conning Designs for Future Super-large Wind Turbines, 11. Basel, Switzerland: Applied Sciences-Basel.

Veers, P., Dykes, K., Lantz, E., Barth, S., and Carlo, L. (2019). Bottasso, Ola Carlson, Andrew Clifton et al. "Grand challenges in the science of wind energy. Science 366, 6464. doi:10.1126/science.aau2027 expected, as the goal of wind energy research is to help the technological development of new, environmentally-friendly and cost-effective large wind turbines.

\section{AUTHOR CONTRIBUTIONS}

The guest editor team has now completed the research topic management. WJZ mainly contributed on collecting abstracts, manuscripts as well as connecting the reviewers and authors. WZS and TK shared a lot of experience on finding reviewers and contributors who enhanced the influence of the topic.

\section{FUNDING}

The special issue was funded by the National Nature Science Foundation under grant number 11672261 and the key programs of the Ministry of Science and Technology under grant number 2019YFE0192600.

\section{ACKNOWLEDGMENTS}

This Special Issue would not be possible without the contributions of various talented authors, professional reviewers, and the dedicated editorial team of Frontiers. Congratulations to all the authors. We would like to take this opportunity to record our sincere gratefulness to all the reviewers. Finally, We place our gratitude to the editorial team of Frontiers and Professor David Wood who launched the new research topic.

Yao, S. L., Chetan, M., Griffith, D. T., Mendoza, A. S. E., Selig, M. S., Martin, D., et al. (2021). Aero-structural Design and Optimization of $50 \mathrm{MW}$ Wind Turbine with over 250- $m$ Blades. London, England: WIND ENGINEERING.

Zhu, W. J., Shen, W. Z., and Sørensen, J. N. (2014). Integrated Airfoil and Blade Design Method for Large Wind Turbines. Renew. Energ. 70, 172-183. doi:10.1016/j.renene.2014.02.057

Conflict of Interest: The authors declare that the research was conducted in the absence of any commercial or financial relationships that could be construed as a potential conflict of interest.

Publisher's Note: All claims expressed in this article are solely those of the authors and do not necessarily represent those of their affiliated organizations, or those of the publisher, the editors and the reviewers. Any product that may be evaluated in this article, or claim that may be made by its manufacturer, is not guaranteed or endorsed by the publisher.

Copyright (c) $2021 \mathrm{Zhu}$, Shen and Kim. This is an open-access article distributed under the terms of the Creative Commons Attribution License (CC BY). The use, distribution or reproduction in other forums is permitted, provided the original author(s) and the copyright owner(s) are credited and that the original publication in this journal is cited, in accordance with accepted academic practice. No use, distribution or reproduction is permitted which does not comply with these terms. 